Article

\title{
Investigation of Gas-Sensitive Properties of Thin-Film Thermovoltaic Sensor Elements Based on Zinc Oxide
}

\author{
Igor Pronin ${ }^{1,2}, * \mathbb{C}$, Nadejda Yakushova ${ }^{1}$, Igor Averin ${ }^{1}$, Andrey Karmanov ${ }^{1}$, \\ Vyacheslav Moshnikov ${ }^{2}$ and Dimitre Dimitrov ${ }^{3}$ \\ 1 Department of Nano- and Microelectronics, Penza State University, Penza 440026, Russia; \\ yand93@mail.ru (N.Y.); nano-micro@mail.ru (I.A.); starosta07km1@mail.ru (A.K.) \\ 2 Department of Micro- and Nanoelectronics, St-Petersburg State Electrotechnical University, \\ St. Petersburg 197376, Russia; vamoshnikov@mail.ru \\ 3 Department of General and Inorganic Chemistry, Sofia University, St. Kliment Ohridski, Sofia 1504, Bulgaria; \\ dimitrov2001@yahoo.com \\ * Correspondence: pronin_i90@mail.ru; Tel.: +7-987-502-59-85
}

Received: 22 September 2019; Accepted: 23 October 2019; Published: 24 October 2019

\begin{abstract}
Systematic research on a new type of gas sensor devices based on the thermovoltaic effect in zinc oxide, inhomogeneously doped with impurities of variable valence, is presented in the article. The $\mathrm{ZnO}-\mathrm{ZnO}-\mathrm{Me}$ two-layer sandwich structure, in which the thermovoltaic effect is observed, is synthesized using sol-gel technology from sols by dissolving the inorganic zinc salt in alcohol and adding a surfactant, followed by the mixing and maturation of the sol. The lower layer of the nanostructure is formed from pure zinc oxide by immersing the substrate at $2 / 3$ length in sol and drying. The upper layer of zinc oxide doped with copper or iron is formed by two or three immersions of the other end of the substrate by $2 / 3$ length, followed by drying and annealing. It has been established that, based on the developed sensor device, it is possible to obtain an increased response to gas-analyzers (ethanol being an example).
\end{abstract}

Keywords: gas sensor; thermovoltaic effect; zinc oxide; spontaneous voltage generation

\section{Introduction}

Lowering operating temperatures and an increase in sensitivity and selectivity are some of the main tasks for modern gas sensors [1-3]. Currently, the industry produces sensors obtained using expensive methods and equipment to create and maintain a certain level of vacuum in the working chamber. The main one is the magnetron sputtering method [4,5]. Sol-gel technology methods, using both centrifugation and dipping operations to form gas-sensitive layers, are promising as an alternative to traditional methods [6].

The advantage of sol-gel methods for producing gas-sensitive sensors is the possibility of obtaining hierarchical network structures with geometric branch sizes commensurate with the value of the Debye screen length [7]. This ensures a high distribution uniformity of the sensitive nanoelements of hierarchical structures on the surface of the adsorbent.

ZnO-based composites doped with transition metals are increasingly being studied as promising nanomaterials [8]. For example, the authors of [9] considered that $\mathrm{Fe}^{3+}$ ions replace $\mathrm{Zn}^{2+}$ ions, forcing them into the internodes. The ionization energy of $\mathrm{Fe}^{2+}$ significantly exceeds the ionization energy of $\mathrm{Fe}^{3+}$, which leads to a decrease in the concentration of conduction electrons and an increase in resistance. However, electrical measurements of the $\mathrm{ZnO}$ :Fe samples [10] have shown that the concentration of charge carriers at the level of which they alloy with iron at 1 at. $\%$ increases from $2.76 \times 10^{18}$ to 3.92 
$\times 10^{19} \mathrm{~cm}^{-3}$. The authors of [11] experimentally established that doping with iron a thin ZnO film promotes a high sensitivity to ethanol at room temperature.

The authors first discovered the thermovoltaic effect in $\mathrm{ZnO} / \mathrm{ZnO}: \mathrm{Me}(\mathrm{Me}=\mathrm{Fe}, \mathrm{Cu})$ homojunctions [12,13]. To explain this effect, the Mott dielectric theory was applied. According to the proposed model, the valency of the impurity in the sample changes, an excess concentration of charge carriers in the doped region occurs, and they diffuse into the undoped part at a certain critical temperature. As a result of this process, a counteracting field and an electromotive force appear. The authors' conclusions on the effect of spontaneous voltage generation (SVG) in nanostructures based on nonuniformly doped zinc oxide were experimentally confirmed by other research teams. In particular, the appearance of a thermovoltaic response in two-layer thin-film $\mathrm{ZnO} / \mathrm{ZnO}-\mathrm{Fe}$ structures with a maximum modulus of $1200 \mu \mathrm{V}$ at a temperature of $673 \mathrm{~K}$ was shown in [14]. Based on this effect, we first proposed the creation of a new type of potentiometric gas sensors based on the thermovoltaic effect [15]. This paper presents a systematic study of sensory elements of this type.

\section{Materials and Methods}

The method for obtaining laboratory samples of sandwich structures is given in our paper [13]. We provide it in a shortened form here.

Film-forming sols were prepared by dissolving zinc acetate $\left(\mathrm{CH}_{3} \mathrm{COO}\right)_{2} \mathrm{Zn} \cdot 2 \mathrm{H}_{2} \mathrm{O}$ and iron nitrate $\mathrm{Fe}\left(\mathrm{NO}_{3}\right)_{3} \cdot 9 \mathrm{H}_{2} \mathrm{O}$ in 2-methoxyethanol $\mathrm{CH}_{3} \mathrm{OCH}_{2} \mathrm{CH}_{2} \mathrm{OH}$ followed by the addition of monoethanolamine $\mathrm{HOCH}_{2} \mathrm{CH}_{2} \mathrm{NH}_{2}$ as a surfactant. Films obtained from sols were applied by immersing the coated sample in a film-forming solution. To obtain the desired film thickness, multiple immersions were carried out, followed by drying for $30 \mathrm{~min}$ at $80^{\circ} \mathrm{C}$ after each immersion. The final annealing of the films was carried out at a temperature of $500{ }^{\circ} \mathrm{C}$ for one hour. The lower, undoped $\mathrm{ZnO}$ layer was formed by three immersions for all samples into the sol. The upper layer of the doped oxide was formed by two and three immersions into the sol solution, while the iron concentration in the films did not change.

The gas-sensitive and electrophysical properties of the fabricated structures were studied by measuring the electromotive force arising in the samples due to the thermovoltaic effect, with one end of the virtual thermocouple being a contact on the $\mathrm{ZnO}$ layer near the $\mathrm{ZnO} / \mathrm{ZnO}$ :Fe interface, and the second is the contact on the $\mathrm{ZnO}$ :Fe surface.

The different sensing junction structures were tested by the means of a novel experimental setup specially designed for checking the temperature dependence of the potential difference of the different junction structures in the air and the changes in the value of the potential difference when these structures are exposed to mixture of vapor of ethanol vapor with dry air flow [16]. To be able to calculate the concentration of ethanol into the quartz tube (where the sample was placed), it was necessary to take the vapor pressure of the ethanol in that condition into account (the temperature in the laboratory and atmospheric pressure). We calculated the vapor pressure of the ethanol by using the equation of Clausius-Claiperon.

\section{Results and Discussion}

\subsection{Investigation of Electromotive Force Temperature Dependence Arising in $\mathrm{ZnO} / \mathrm{ZnO}-\mathrm{Me}$ in Ethanol Vapor Atmosphere}

Figure 1 shows comparative temperature dependences of the electromotive force (EMF) in the air and in ethanol vapors with a concentration of $1000 \mathrm{ppm}$ for samples, the upper layer of which was formed by two immersions. 


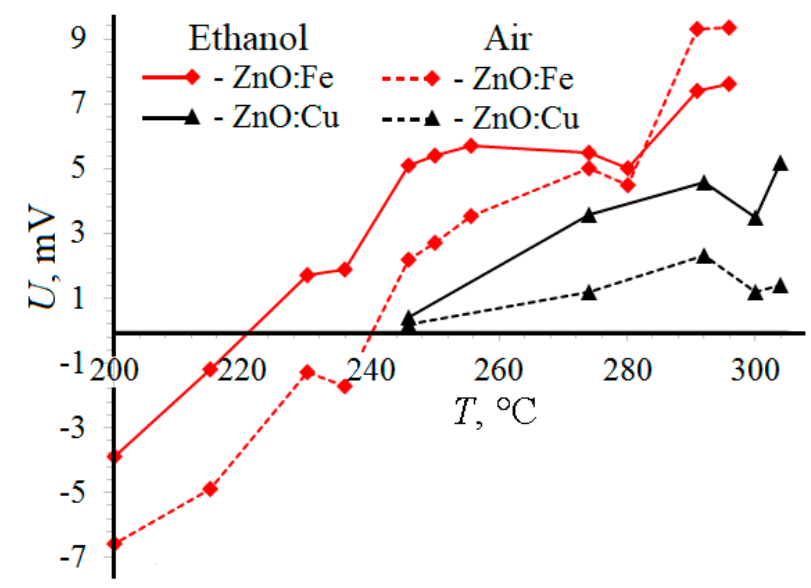

Figure 1. Temperature dependence of the electromotive force in $\mathrm{ZnO} / \mathrm{ZnO}-\mathrm{Me}$ structures with the upper layer formed by two immersions in an ethanol atmosphere of $1000 \mathrm{ppm}$.

The analysis of the presented dependences shows that the EMF values for the $\mathrm{ZnO} / \mathrm{ZnO}-\mathrm{Cu}$ samples were higher in the ethanol atmosphere in the considered entire temperature range. A similar situation was observed in the range of $200-280^{\circ} \mathrm{C}$ for the $\mathrm{ZnO} / \mathrm{ZnO}-\mathrm{Fe}$ samples; however, this ratio changed at $T>280^{\circ} \mathrm{C}$. To explain the obtained dependences, we considered the interaction mechanisms of ethanol with the surface of the sensor element. The surface sensitivity of the semiconductor oxides to ethanol was determined by the following processes [17]:

$$
\begin{gathered}
\mathrm{C}_{2} \mathrm{H}_{5} \mathrm{OH} \rightarrow \mathrm{C}_{2} \mathrm{H}_{4}+\mathrm{H}_{2} \mathrm{O} \\
\beta \times \mathrm{C}_{2} \mathrm{H}_{5} \mathrm{OH}+\mathrm{O}_{\beta(\text { ads })}^{\alpha-} \rightarrow \beta \times \mathrm{CH}_{3} \mathrm{COH}+\beta \times \mathrm{H}_{2} \mathrm{O}+\alpha \times \mathrm{e}^{-}
\end{gathered}
$$

The first mechanism of ethanol dehydration with the formation of ethylene predominantly occurs at Brönsted centers, and the second one takes place at Lewis centers [18].

Thus, the occurrence of a chemoresistive effect was caused by the oxidation of ethanol with chemisorbed oxygen, followed by the release of electrons into the conduction band of the semiconductor. Let us consider the influence of these processes on the EMF value generated in the samples.

In all types of structures, the bottom layer is an undoped film of the zinc oxide interacting with the atmosphere of $1 / 3$ area of the substrate. The film thickness is comparable to the Debye screening length; therefore, the approximation of flat zones takes place. When ethanol vapor is exposed to the film, it is enriched with free electrons, which brings the Fermi level closer to the bottom of the conduction band. In the case of the $\mathrm{ZnO} / \mathrm{ZnO}-\mathrm{Cu}$ samples, this leads to a height increase of the potential barrier, and in the case of the $\mathrm{ZnO} / \mathrm{ZnO}-\mathrm{Fe}$ samples, it causes the opposite effect.

When ethanol vapors interact with the surface of the upper doped layer of the zinc oxide, the situation changes depending on the type of film conductivity. Thus, in the case of $\mathrm{ZnO}-\mathrm{Fe}$, which has n-type conductivity, the interaction with ethanol enriches the material with electrons. This, in turn, leads to a decrease in the threshold temperature for the appearance of a phase transition and an increase in the EMF value over the entire temperature range. This pattern is shown in Figure 1 for a series of the $\mathrm{ZnO} / \mathrm{ZnO}-\mathrm{Fe}$ samples. It should be noted that enrichment takes place by a thickness of the Debye screening depth order, which, in the case of strong doping, becomes much smaller than the film thickness.

The EMF reduction in the ethanol atmosphere at $T>280^{\circ} \mathrm{C}$ compared with the values obtained in the air can be explained by intensive processes of electron capture from a semiconductor during the transition between different forms of oxygen [19].

In the case of $\mathrm{ZnO}-\mathrm{Cu}$ films with p-type conductivity, exposure to ethanol vapors leads to surface depletion and, at some pore concentration, to inversion. In this case, there was the possibility of $n-p^{+}-n$ structure formation, and the polarity of the resulting EMF cannot be ruled out. 
In the case shown in Figure 1 for the $\mathrm{ZnO} / \mathrm{ZnO}-\mathrm{Cu}$ system, a potential barrier with an inversion layer most likely already existed under the point contact. Under the influence of ethanol vapors, this thin inversion layer was enriched with electrons, and the surface of the p-type region was depleted. The latter process took place in a thin surface layer, the depth of which corresponded to the Debye screening depth; therefore, it is likely that the enrichment of the inversion layer made the main contribution to increasing the EMF values when ethanol was exposed to the sensor.

Figure 2 shows the EMF temperature dependence in $\mathrm{ZnO} / \mathrm{ZnO}-\mathrm{Me}$ structures, the upper layer of which was formed by three immersions in an ethanol atmosphere with a concentration of $1000 \mathrm{ppm}$.

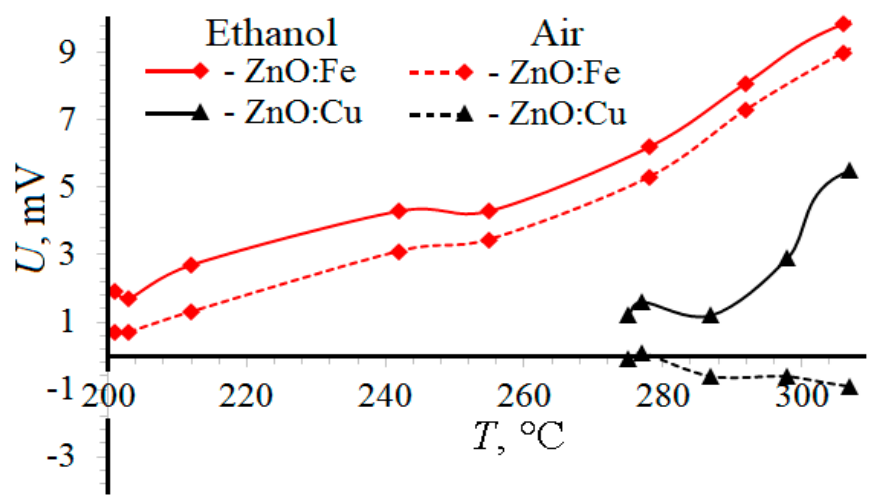

Figure 2. Temperature dependence of the electromotive force in $\mathrm{ZnO} / \mathrm{ZnO}-\mathrm{Me}$ structures with the upper layer formed by three immersions in the ethanol atmosphere of $1000 \mathrm{ppm}$.

The results obtained were similar to those shown in Figure 2. In the case of the $\mathrm{ZnO} / \mathrm{ZnO}-\mathrm{Fe}$ samples, the upper layer was also enriched with electrons, which led to an increase in the EMF value in ethanol vapors compared with the air atmosphere over the entire range of studied temperatures. In the $\mathrm{ZnO} / \mathrm{ZnO}-\mathrm{Cu}$ samples, a polarity reversal of the resulting EMF was observed. This was probably due to the formation of an inversion layer on the film surface near the point contact due to the action of reducing gas vapors. As noted above, in this case, the $n-p^{+}-n$ structure may have occurred, which resulted in a polarity change. The threshold at which inversion occurred was less than $30 \mathrm{ppm}$.

\subsection{Investigation of the Emerging EMF Dependence on the Concentration of Ethanol Vapor in the Atmosphere}

Figure 3 shows the concentration dependence of the electromotive force for the $\mathrm{ZnO} / \mathrm{ZnO}-\mathrm{Fe}$ samples taken at a temperature of $200{ }^{\circ} \mathrm{C}$. As noted earlier, in the case of formation of the upper layer by two immersions in a sol, the film was enriched with main charge carriers, including the region under the point contact. This led to an increase in the EMF with concentration growth of ethanol $C$ vapors (marked with a solid line).

In the case of the samples, the upper layer of which was formed by three immersions, the polarity of the EMF changed due to a number of the reasons described above. With an increase in the concentration of ethanol vapor, a depletion of the inversion layer under a point probe was observed, which led to a decrease in the EMF value. This process likely made the main contribution to the form of the presented dependence, despite the enrichment processes in the lower undoped $\mathrm{ZnO}$ layer and in the upper layer. 


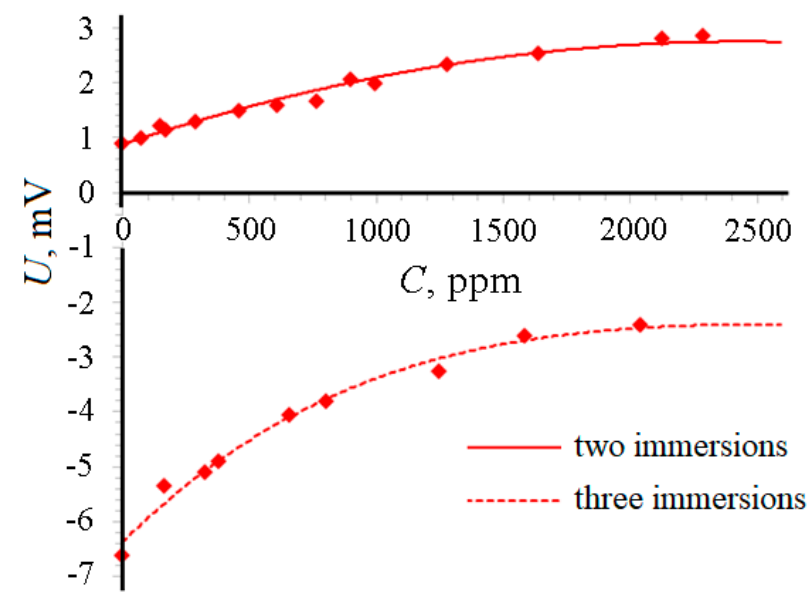

Figure 3. Concentration dependence of the electromotive force for the $\mathrm{ZnO} / \mathrm{ZnO}-\mathrm{Fe}$ samples $\left(T=200{ }^{\circ} \mathrm{C}\right)$.

The obtained dependences $U(C)$ are described well enough by the following approximating function:

$$
U(C)=A_{1} \ln (C)+A_{2}
$$

where $A_{1}$ and $A_{2}$ are constants depending on the synthesis regimes of semiconductor films.

Figure 4 shows the concentration dependence of the electromotive force for the $\mathrm{ZnO} / \mathrm{ZnO}-\mathrm{Cu}$ samples taken at the temperature of $300^{\circ} \mathrm{C}$. Both series of samples showed an increase in the emerging EMF with increasing ethanol vapor concentration. As noted earlier, it seems that these processes were determined by an increase in the electron concentration in the inversion layer under the point contact due to the reducing properties of the gas-analyzer.

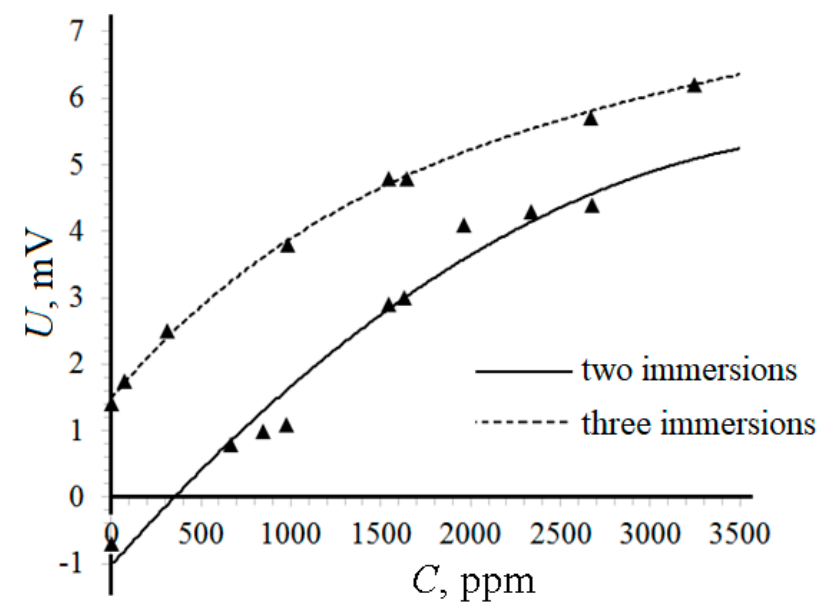

Figure 4. Concentration dependence of the electromotive force for the $\mathrm{ZnO} / \mathrm{ZnO}-\mathrm{Cu}$ samples $\left(T=300^{\circ} \mathrm{C}\right)$.

It should be noted that for the samples, the upper layer of which was formed by two immersions in the sol, the dependence $U(C)$ changed the sign, passing through zero at $C \approx 300 \mathrm{ppm}$. This probably indicates the appearance of an inversion layer under the contact at a given gas concentration due to its reducing properties. 


\subsection{Investigation of the Sensory Response Dependence of $\mathrm{ZnO} / \mathrm{ZnO}-\mathrm{Me}$ Structures on Ethanol Vapor} Concentration and Temperature

The dependence of gas sensitivity on the concentration of the gas-analyzer and the temperature is of particular interest for the development of gas sensors. We can calculate the gas sensitivity as a module of the relative change in the electromotive force when exposed to the gas-analyzer sensor, expressed as a percentage [15]:

$$
S=\left|\left(U_{\text {gas }}-U_{\text {air }}\right) / U_{\text {air }}\right| \times 100 \%
$$

where $U_{g a s}$ and $U_{a i r}$ are potential differences in ethanol vapor and in the air, respectively.

Figure 5 shows the calculated $S(C)$ curves for the $\mathrm{ZnO} / \mathrm{ZnO}-\mathrm{Fe}$ samples for the temperature of $200{ }^{\circ} \mathrm{C}$.

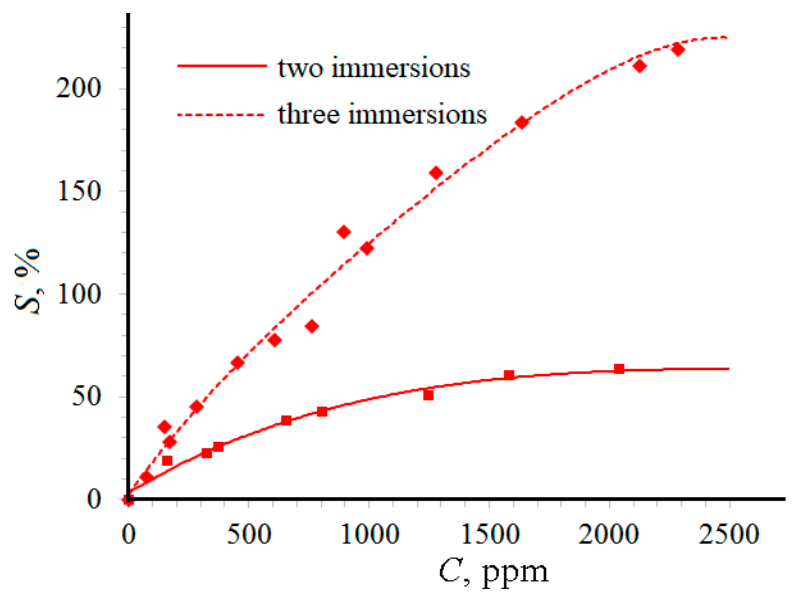

Figure 5. Concentration dependence of gas sensitivity for the $\mathrm{ZnO} / \mathrm{ZnO}-\mathrm{Fe}$ samples $\left(T=200^{\circ} \mathrm{C}\right)$.

It can be seen from Figure 5 that gas sensitivity of the samples, the upper layer of which was formed by three immersions, was greater than that of the others in the entire range of concentrations studied. It is likely that the main reason for this pattern was associated with a significant concentration modulation of charge carriers in the inversion layer under the point contact that occurred in these samples. In general, the obtained dependences could quite accurately be approximated by the function $S(C)=f(\sqrt{ } C)$. $300{ }^{\circ} \mathrm{C}$

Figure 6 shows the calculated curves $S(C)$ for the $\mathrm{ZnO} / \mathrm{ZnO}-\mathrm{Cu}$ samples at the temperature of

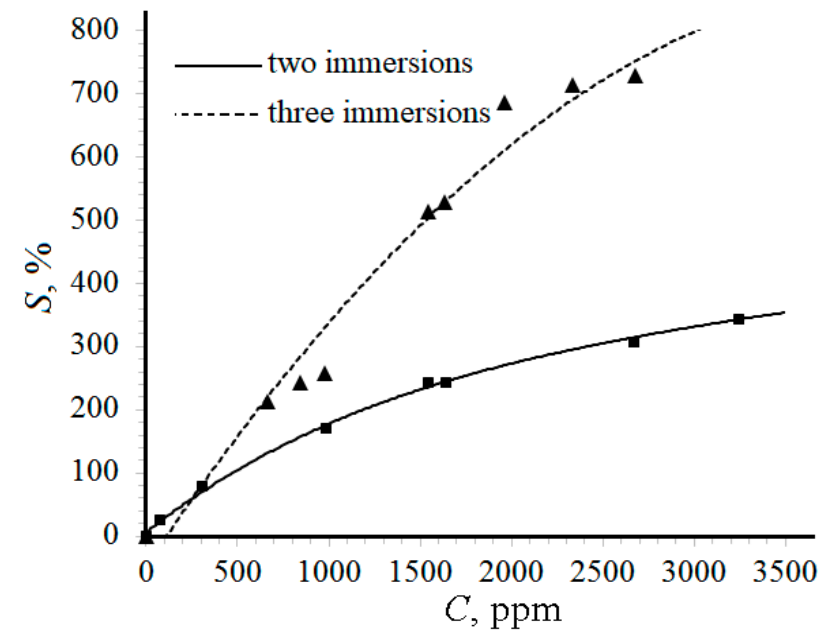

Figure 6. Concentration dependence of gas sensitivity for the $\mathrm{ZnO} / \mathrm{ZnO}-\mathrm{Cu}$ samples $\left(\mathrm{T}=300{ }^{\circ} \mathrm{C}\right)$. 
An analysis of the graphs shows similar results for the $\mathrm{ZnO} / \mathrm{ZnO}-\mathrm{Fe}$ system. As can be seen, the samples, the upper layer of which was formed by three immersions, showed greater gas sensitivity values in the entire range of the studied concentrations. The dependences $S(C)$ for these samples could also be quite accurately approximated by the square root function of the gas analyzer concentration.

An analysis of the surface fractal dimension of the upper layer of the doped zinc oxide depending on the number of forming it immersions allowed us to establish a correlation between the $D_{f}$ and $S$ values. Figure 7 shows the relationship between the surface fractal dimension of the samples calculated by the perimeter-area method and the gas sensitivity value at ethanol vapor concentration of 1000 ppm (the temperature corresponded to the maximum gas sensitivity).

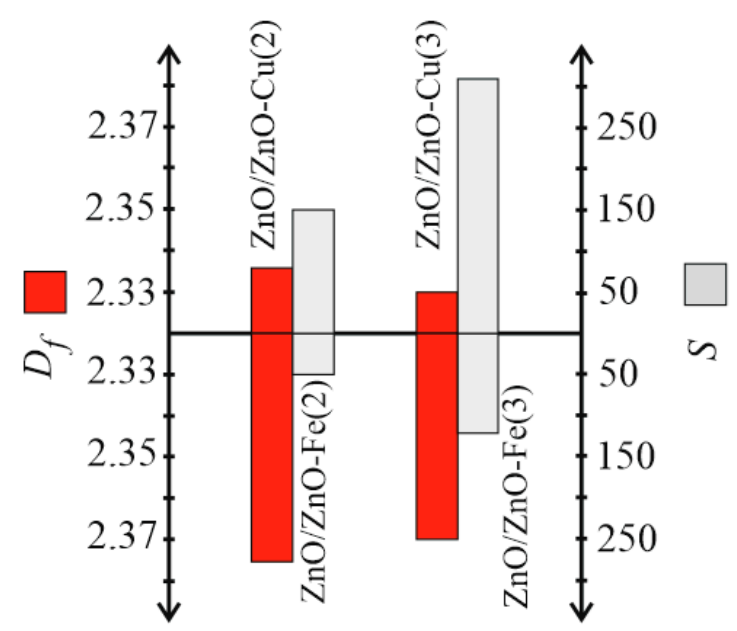

Figure 7. Correlation between the surface fractal dimension of the samples calculated by the perimeter-area method and the gas sensitivity value at ethanol vapor concentration of $1000 \mathrm{ppm}$.

It can be seen from Figure 7 that the following pattern held for both systems: As the surface fractal dimension decreased, the gas sensitivity of the samples increased. The value of $D_{f}$ decreased with an increase in the number of immersions for the formation of films. It should be specially noted that the samples, the upper layer of which was formed by one immersion in sol, had a maximum surface fractal dimension but a minimum gas sensitivity; therefore, these samples were not considered in the work.

Thus, there was a relationship between the surface fractal dimension of nanostructured films and the imperfection of the oxide structure, which was reflected in their gas-sensing properties. This fact can be used to develop methods for the express diagnostics of the gas-sensing properties of semiconductor sensors.

Figure 8 shows the temperature dependence of gas sensitivity for all investigated series of samples. It can be seen that all samples had a similar character of $S(T)$ dependence in the studied temperature range, with the exception of $\mathrm{ZnO} / \mathrm{ZnO}-\mathrm{Fe}$, the upper layer of which was formed by three immersions in sol.

At low temperatures, when it was possible to detect the emerging EMF, the sensitivity increased to a certain maximum, and then it decreased. When a certain temperature was reached, the gas sensitivity function experienced a minimum and increased to a second maximum, after which it decreased again.

In the case of the $\mathrm{ZnO} / \mathrm{ZnO}-\mathrm{Fe}$ samples, the upper layer of which was formed by three immersions, the dependence of its sensitivity on ethanol decreased exponentially in the studied temperature range. This sample was distinguished by the lowest gas sensitivity values and the absence of a thin inversion layer under point contact in the entire studied range of temperatures and concentrations.

All physical processes leading to the results obtained have been previously analyzed. 


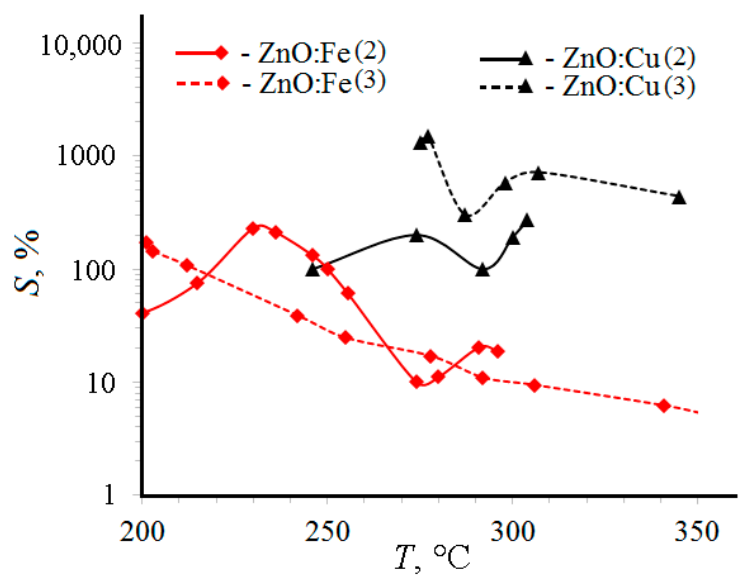

Figure 8. Temperature dependence of gas sensitivity for the $\mathrm{ZnO} / \mathrm{ZnO}-\mathrm{Me}$ samples.

\section{Conclusions}

Thus, a systematic study of novel potentiometric gas sensor elements based on the thermovoltaic effect arising in the $\mathrm{ZnO} / \mathrm{ZnO}-\mathrm{Me}$ samples was carried out for the first time. An analysis of the obtained results showed the prospects of using the thermovoltaic effect in sensor elements for detection of various gas-analyzers. Figures 1 and 2 show that ethanol exposure with a concentration of $1000 \mathrm{ppm}$ led to an increase in the electromotive force arising in homojunctions by $1.5-2 \mathrm{mV}$ over the entire temperature range. Moreover, the thickness of the upper layer doped by metal cations significantly affected the sensitization result. For all samples, the upper layer of which was formed by two immersions (as well as for the $\mathrm{ZnO}-\mathrm{ZnO}(\mathrm{Fe})$ sample, the upper layer of which was formed by three immersions), the dependence curves of the EMF on the temperature in air and ethanol vapor behaved symbatically.

However, for the $\mathrm{ZnO}-\mathrm{ZnO}(\mathrm{Cu})$ sample, the upper layer of which was formed by three immersions in sol, the EMF dependence on temperature in ethanol vapors was an increasing function, and it was a decreasing one in air vapors. In addition, there was a change in the polarity of the EMF. This opens up additional possibilities for controlling the magnitude of the sensor response and the operating temperatures of sensor elements. An analysis of dependences of the EMF arising in the samples on the concentration of ethanol vapors was well described by the logarithmic function for all series of samples. At the same time, the $\mathrm{ZnO}-\mathrm{ZnO}(\mathrm{Cu})$ samples, the upper layer of which was formed by three immersions in sol, had the maximum sensitivity to ethanol with a concentration of $2500 \mathrm{ppm}$. A minimum sensitivity was observed for $\mathrm{ZnO}-\mathrm{ZnO}(\mathrm{Fe})$ samples, the upper layer of which was formed by three immersions (only $50 \%$ for $2500 \mathrm{ppm})$. Moreover, over the entire temperature range, the $\mathrm{ZnO}-\mathrm{ZnO}(\mathrm{Cu})$ samples showed larger sensory responses (a maximum value of $1100 \%$ was observed at a temperature of about $280{ }^{\circ} \mathrm{C}$ for the $\mathrm{ZnO}-\mathrm{ZnO}(\mathrm{Cu})-3$ samples at an ethanol vapor concentration of $1000 \mathrm{ppm})$.

It is also worth noting the revealed correlation between the surface fractal dimension of the upper layer modified by metal cations and the sensory responses of the samples: A decrease in sensory response with increasing fractality was observed for all series. Moreover, fractal dimension values were in the range $2.33-2.37$ for all samples, which indirectly indicates their developed surface.

Author Contributions: Conceptualization, I.P. and V.M.; formal analysis, I.A. and V.M.; investigation, I.P. and N.Y.; methodology, D.D.; software, A.K.; visualization, A.K.

Funding: This work was supported by the Ministry of Education and Science of the Russian Federation, project No. 16.897.2017/4.6.

Conflicts of Interest: The authors declare no conflict of interest.

\section{References}

1. Kaur, J.; Roy, S.C.; Bhatnagar, M.C. Highly sensitive $\mathrm{SnO}_{2}$ thin film $\mathrm{NO}_{2}$ gas sensor operating at low temperature. Sens. Actuators B 2007, 123, 1090-1095. [CrossRef] 
2. Proença, M.; Rodrigues, M.S.; Borges, J.; Vaz, F. Gas sensing with nanoplasmonic thin films composed of nanoparticles $(\mathrm{Au}, \mathrm{Ag})$ dispersed in a $\mathrm{CuO}$ matrix. Coatings 2019, 9, 337. [CrossRef]

3. Laurenti, M.; Cauda, V. Porous zinc oxide thin films: Synthesis approaches and applications. Coatings 2018, 8, 67. [CrossRef]

4. Kim, S.H.; Shim, G.I.; Choi, S.Y. Fabrication of Nb-doped ZnO nanowall structure by RF magnetron sputter for enhanced gas-sensing properties. J. Alloys Compd. 2017, 698, 77-86. [CrossRef]

5. Hammadi, O.A.; Naji, N.E. Characterization of polycrystalline nickel cobaltite nanostructures prepared by DC plasma magnetron co-sputtering for gas sensing applications. Photon. Sens. 2018, 8, 43-47. [CrossRef]

6. Gaspera, E.; Martucci, A. Sol-gel thin films for plasmonic gas sensors. Sensors 2015, 15, 16910-16928. [CrossRef] [PubMed]

7. Dimitrov, D.T.; Nikolaev, N.K.; Papazova, K.I.; Krasteva, L.K.; Bojinova, A.S.; Peshkova, T.V.; Kaneva, N.V.; Pronin, I.A.; Averin, I.A.; Yakushova, N.D.; et al. Investigation of the electrical and ethanol-vapor sensing properties of the junc-tions based on $\mathrm{ZnO}$ nanostructured thin film doped with copper. Appl. Surf. Sci. 2017, 392, 95-108. [CrossRef]

8. Qu, J.; Ge, Y.; Zu, B.; Li, Y.; Dou, X. Transition-metal-doped p-type zno nanoparticle-based sensory array for instant discrimination of explosive vapors. Small 2016, 12, 1369-1377. [CrossRef]

9. Dinesha, M.L.; Jayanna, H.S.; Ashoka, S.; Chandrappa, G.T. Temperature dependent electrical conductivity of Fe doped $\mathrm{ZnO}$ nanoparticles prepared by solution combustion method. J. Alloy. Compd. 2009, 485, 538-541. [CrossRef]

10. $\mathrm{Xu}, \mathrm{L}$;; $\mathrm{Li}, \mathrm{X}$. Influence of Fe-doping on the structural and optical properties of $\mathrm{ZnO}$ thin films prepared by sol-gel method. J. Cryst. Growth 2010, 312, 851-855. [CrossRef]

11. Kuo, G.H.; Wang, H.P.; Hsu, H.H.; Wang, J.; Chiu, Y.M.; Jou, C.J.; Chen, F.L. Sensing of ethanol with nanosize Fe-ZnO thin films. J. Nanomater. 2009, 2009, 4. [CrossRef]

12. Pronin, I.A.; Averin, I.A.; Karmanov, A.A.; Yakushova, N.D.; Bozhinova, A.S.; Dimitrov, D.T.; Papazova, K.I.; Georgieva, A.T.; Moshnikov, V.A.; Terukov, E.I. The thermovoltaic effect in zinc oxide inhomogeneously doped with mixed-valence impurities. Tech. Phys. Lett. 2015, 41, 930-932. [CrossRef]

13. Pronin, I.; Yakushova, N.; Averin, I.; Karmanov, A.; Moshnikov, V.; Dimitrov, D. Development of a physical model of thermovoltaic effects in the thin films of zinc oxide doped with transition metals. Coatings 2018, 8 , 433. [CrossRef]

14. Kalinin, Y.E.; Makagonov, V.A.; Pankov, S.Y.; Sitnikov, A.V. Electrical properties of two-layer Zn/ZnO-Fe thin-film structures. Vestn. Voronezhskogo Gos. Tekhnicheskogo Univ. 2016, 12, 66-70. (in Russian)

15. Pronin, I.A.; Yakushova, N.D.; Dimitrov, D.T.; Krasteva, L.K.; Papazova, K.I.; Karmanov, A.A.; Averin, I.A.; Georgieva, A.T.; Moshnikov, V.A.; Terukov, E.I. A New type of gas sensor based on the thermovoltaic effect in zinc oxide inhomogeneously doped with mixed-valence impurities. Tech. Phys. Lett. 2017, 43, 825-827. [CrossRef]

16. Gracheva, I.E.; Maksimov, A.I.; Moshnikov, V.A.; Plekh, M.E. A computer-aided setup for gas-sensing measurements of sensors based on semiconductor nanocomposites. Instrum. Exp. Tech. 2008, 51, 462-465. [CrossRef]

17. Sysoev, V.V.; Button, B.K.; Wepsiec, K.; Dmitriev, S.; Kolmakov, A. Toward the nanoscopic "electronic nose": Hydrogen vs carbon monoxide discrimination with an array of individual metal oxide nano- and mesowire sensors. Nano Lett. 2006, 6, 1584-1588. [CrossRef] [PubMed]

18. Karpova, S.S.; Moshnikov, V.A.; Mjakin, S.V.; Kolovangina, E.S. Surface functional composition and sensor properties of $\mathrm{ZnO}, \mathrm{Fe}_{2} \mathrm{O}_{3}$ and $\mathrm{ZnFe}_{2} \mathrm{O}_{4}$. Semiconductors 2013, 47, 392-395. [CrossRef]

19. Gurwitz, R.; Cohen, R.; Shalish, I. Interaction of light with the ZnO surface: Photon induced oxygen "breathing," oxygen vacancies, persistent photoconductivity, and persistent photovoltage. J. Appl. Phys. 2014, 115, 033701. [CrossRef]

(C) 2019 by the authors. Licensee MDPI, Basel, Switzerland. This article is an open access article distributed under the terms and conditions of the Creative Commons Attribution (CC BY) license (http://creativecommons.org/licenses/by/4.0/). 